\title{
Interações entre Candida albicans e Hospedeiro
}

\section{Interactions Between Candida albicans and Host}

\author{
Tatiane De Rossi ${ }^{1 *}$; Marcell Alysson Batisti Lozovoy ${ }^{1}$; Rosiane Valeriano da \\ Silva $^{1}$; Eduardo Vignoto Fernandes ${ }^{1}$; Thais Herrero Geraldino ${ }^{1}$; Ivete Conchon \\ Costa $^{2}$; Halha Ostrenski Saridakis 3 ; Maria Angelica Ehara Watanabe \\ Ionice Felipe ${ }^{5}$
}

\section{Resumo}

Candida albicans pode causar graves infecções em pacientes que estão imunocomprometidos por doenças, por cirurgias ou por terapia imunossupressiva. Os altos níveis de morbidade e mortalidade resultantes de infecções em pacientes hospitalizados mostraram que $C$. albicans tornou-se um patógeno humano de grande relevância clínica. Mesmo o sistema imune sendo o principal fator que define a transição do fungo de comensal para patogênico, fatores de virulência expressos por C. albicans, tais como adesinas, mudança fenotípica, comportamento dimórfico, e secreção de enzimas hidrolíticas, podem contribuir para a persistência da colonização, assim como o desenvolvimento de episódios sintomáticos. A defesa do hospedeiro compreende ingestão e eliminação do fungo por células fagocíticas que possuem vários receptores, como o Toll-4, dectina-1 associado a receptores tipo Toll-2 e receptores de manose. A interleucina-10 (IL-10) produzida por fagócitos determina a susceptibilidade do hospedeiro a infecção fúngica, enquanto a IL-10 produzida por células T reguladoras é responsável pelo comensalismo. Em contraste, a produção de fator de necrose tumoral- $\alpha$ (TNF- $\alpha$ ), interleucina -1 $\beta$ (IL-1 $\beta$ ), (IL-6), (Il-12) e IL-17 conferem imunidade protetora. O interferon- $\gamma$ (IFN- $\gamma$ ) produzido por células natural "killer" e células Th1 estimula a migração de fagócitos e maior eficácia na destruição do fungo. Nas células epiteliais de mucosas os receptores NOD-like e defensinas- $\beta$ citoplasmáticos evitam a translocação de $C$. albicans da microbiota para os tecidos os quais são modulados por citocinas IL-1 $\beta$,IL-17 e IL-22.

Palavras-chave: Resposta imune, TH1, TH2, TH17, Treg.

\begin{abstract}
Candida albicans can cause grave infections in patients who are immunocompromised by diseases, by surgery, or by immunesupresive therapy. The high levels of morbidity and mortality resulting from those infections in hospitalized patients show that $C$. albicans became a prominent human pathogen. Although the host immune system is the major factor balancing the transition from commensalisms
\end{abstract}

\footnotetext{
1 Mestrandos do Programa de Pós-Graduação em Patologia Experimental, Departamento de Ciências Patológicas, Centro de Ciências Biológicas, Universidade Estadual de Londrina. Rodovia Celso Garcia Cid, PR445, Campus Universitário, 86051-990, Londrina, PR. Tel/Fax: (43)3371-4982.*Autor para contato: tatiderossi@hotmail.com. E-mails: thaisherrero@hotmail.com; eduardovignoto@ig.com.br; marcell_lozovoy@hotmail.com; zane.valeriano@hotmail.com

2 Doutora em Microbiologia, docente do Programa de Pós-Graduação em Patologia Experimental, UEL. E-mail: conchon@uel.br

3 Doutora em Ciências pela UNIFESP, docente do Programa de Pós-Graduação em Patologia Experimental, UEL. halhaost@ hotmail.com uel.br

4 Doutora em Bioquímica pela USP-Ribeirão Preto, Pós-Doutorado em Imunologia pela Fundação Hemocentro de Ribeirão Preto, docente do Programa de Pós-Graduação em Patologia Experimental, UEL. E-mail: maewatuel@gmail.com

5 Doutora em Ciências Biológicas (Biofísica) pela UFRJ, Pós-Doutorado pela Washington University, Saint Louis, MO, USA, docente do Programa de Pós-Graduação em Patologia Experimental, UEL. E-mail: ionice@uel.br
} 
to pathogenicity, several virulence attributes expressed by $C$. albicans, such as adhesion factors, phenotypic switching, dimorphic behavior, and secretion of hydrolytic enzymes, might contribute to the persistence of colonization as well as the development of symptomatic episodes. Host defense against candidiasis relies mainly on the ingestion and elimination of C. albicans by phagocytic cells, which present receptors Toll-like 4, dectin-1 associated to receptors Toll-like 2 and mannose receptors. The cytokine IL-10 (IL-10) produced by phagocytes has a crucial role on susceptibility of host fungal infection, whereas IL-10 produced by regulatory $\mathrm{T}$ cells is mainly responsible by commensalisms. In contrast, productions of tumour necrosis factor - $\alpha$ (TNF- $\alpha$ ), interleukin-1 $\beta$ (lL-1 $\beta)$, (IL-6) and (Il-12) provided protective cell-mediated immunity. The interferon- $\gamma$ produced by natural killer and TH1 cells stimulates migration of phagocytes and major efficacy on destruction of fungi. In epithelial cells from mucosas the NOD-like receptors and defensins- $\beta$ cytoplasmatic prevent the translocation of $C$. albicans from microbiota to tissues, which are modulated by IL-1 $\beta$, Il-17 and Il-22 cytokines.

Key words: TH1, TH2, TH17, Treg immune response.

\section{Introdução}

A maior parte das infecções fúngicas nos seres humanos é causada por fungos oportunistas. A Candida é um fungo diplóide e polimórfico responsável pelo desenvolvimento de várias patologias (LIMA et al., 2004; KARKOWSKAKULETA; RAPALA-KOZIK; KOZIK, 2009). Em condições normais, este fungo está presente nos humanos como um organismo comensal sem que isso implique em quaisquer efeitos prejudiciais à sua saúde (CARDOSO, 2004). Entre 25 a 75\% dos indivíduos saudáveis podem apresentar Candida spp. (WILLIAMS et al., 1997). Entre as mulheres, cerca de 20 a $30 \%$ apresentam colonização na mucosa vaginal, sendo Candida albicans a espécie prevalente (OLIVEIRA et al., 1993; VAL; ALMEIDA FILHO, 2001). Podem colonizar a cavidade oral, tratos gastrointestinal, respiratório e urinário, além da circulação sanguínea. A candidíase se manifesta quando fatores predisponentes, fisiológicos, patológicos e mecânicos, modificam o relacionamento que ocorre entre o hospedeiro e a microbiota natural. Ou seja, a relação de comensal é dependente da integridade do tecido do hospedeiro, da microbiota normal assim como do sistema imune. Neste caso a candidíase pode ser localizada, determinando sintomatologia restrita a essa área, ou sistêmica e fatal (SOLL; LOCKHART; ZHAO, 2003; COLOMBO; GUIMARÃES, 2003; PFALLER; DIEKEMA, 2007; JOUAULT et al., 2009).

\section{Manifestações clínicas}

Em pacientes com imunodeficiências ou outras condições predisponentes, espécies de Candida podem causar várias infecções orais incluindo pseudomembranosa, candidíase eritematosa, candidíase hiperplásica, quelite angular e candidíase mucocutânea crônica (CANNON et al., 1995). O uso de anticoncepcionais, antibióticos e as várias formas de imunodeficiências predispõe a candidíase vaginal e podem estar envolvidas em episódios de reinfecção por este fungo (KIRKPATRICK, 1984; COLOMBO; GUIMARÃES, 2003). Segundo Colombo e Guimarães (2003) a candidíase pode manifestarse em locais diferentes do corpo, incluindo órgãos como rins, fígado, baço e cérebro.

Também têm sido relatadas infecções por outras espécies de Candida como a C. tropicalis, C. kruzei e C. glabrata (CORDEIRO et al., 2003; BASTOS et al., 2003). Isolados de C. glabata e C. kruzei de pacientes de um Hospital terciário na Espanha apresentaram resistência ao fluconasol em um estudo "in vitro" e o uso do voriconazole foi indicado como bom candidato à terapêutica de candidemias causado por essas espécies (GUINDÓs et al., 2008).

\section{Fatores de virulência}

Existem algumas propriedades inerentes às 
células de Candida spp., comumente denominadas fatores de virulência, que lhes conferem a capacidade de produzir doença. Para iniciar o processo de infecção ao hospedeiro, a $C$. albicans expressa fatores de virulência tais como: adesividade, alterações fenotípicas e morfológicas que resultam no sucesso do processo infeccioso (CALDERONE; FONZI, 2001). Entre outros fatores envolvidos na transição da forma comensal para patogênica destacam-se a proteção contra lise osmótica (parede celular); liberação de proteases que facilitam que $C$. albicans atravesse o epitélio do hospedeiro; formação de hifas para aumentar a capacidade nutricional e fixação ao tecido (CULTLER, 1991).

O processo inicial de virulência de C. albicans é a sua adesão às células do hospedeiro. Essa ação é de fundamental importância para que o fungo sobreviva aderido ou internalizado pelas células epiteliais. A aderência pode ser mediada por uma variedade de proteínas expressa na superfície do patógeno e envolve uma família de genes, Agglutinin-Like Sequence (ALS) que codificam oito destas proteínas (ZHAO et al., 2004). A expressão das adesinas é ocasionada por condições ambientais ou fisiológicas encontradas no hospedeiro (ÁLVARES; SVLDZLNSKI; CONSOLARO, 2007).

Phan et al. (2007) descobriram que Als3, expressa na superfície de $C$. albicans, é requerida no processo de invasão celular. Esta proteína se liga a caderinas de células endoteliais e células epitelias orais, e estas ligações induzem as células do hospedeiro a endocitar o fungo. Recentemente, Almeida et al. (2008) demonstraram que $C$. albicans na forma de hifa utiliza a adesina Als3 para ligar-se a ferritina no interior de células epiteliais e adquirir o ferro para seu crescimento. Mutantes para Als3 falharam na ligação com a ferritina, cresceram menos com ferritina como fonte de ferro e foram incapazes de danificar as células do hospedeiro, portanto, Als3 além de adesina e invasina confere ao fungo a capacidade de explorar uma fonte de ferro do hospedeiro.

A capacidade dessa espécie em se diferenciar da forma unicelular leveduriforme para a forma filamentosa (hifas ou pseudo-hifas) é denominada dimorfismo morfológico (KULETA; KOZIK; KOZIK, 2009). A alteração de forma representa uma resposta ou condição adaptativa do fungo para sobreviver em condições biológicas diversificadas como temperatura e $\mathrm{pH}$, que variam em demasia do ambiente extra para o intracorporal (ÁLVARES; SVLDZLNSKI; CONSOLARO, 2007). Segundo Kuleta, Kozik e Kozik (2009), as mudanças fenotípicas da C. albicans são condições importantes, principalmente, no processo de invasão ao hospedeiro tornando o fungo mais virulento durante os processos infecciosos.

No processo de invasão ao hospedeiro a $C$. albicans induz as células epiteliais a realizarem “internalização celular”, mecanismo este de fundamental importância para o crescimento e colonização da Candida no organismo do hospedeiro. Essa fagocitose atípica ocorre principalmente por intermédio dos blastoconídios, entretanto, quando esse fungo está na forma de hifa, sua invasão ao hospedeiro acontece através das junções epiteliais, processo denominado "tigmotropismo" (ÁLVARES; SVLDZLNSKI; CONSOLARO, 2007).

Lima et al. (2004) e Braz et al. (2009) consideram que as proteases são de extrema importância no processo de invasão ao hospedeiro porque elas atuam na degradação das barreiras físicas (pele e mucosas), na digestão das proteínas e membranas celulares e também na evasão do fungo dos linfócitos e das células fagocíticas. Rörig, Colacite e Abegg (2009), analisando a capacidade de crescimento em $39^{\circ} \mathrm{C}$ e $42^{\circ} \mathrm{C}$, observaram a produção de enzimas hidrolíticas e a atividade hemolítica de 21 cepas clínicas de sete espécies de Candida spp. e, dentre todas as espécies, C. albicans foi a que apresentou maior potencial de virulência. 
As aspartil proteases (SAPs), compõem uma família de 10 isoenzimas, sendo algumas secretadas (SAPs1-8) e outras que se expõem na parede (SAPs9-10) (HUBE; NAGLIK, 2001). A importância dos genes SAPs nos mecanismos de virulência tem sido relatada em vários trabalhos, com isso, foi evidenciado que cada gene dessa família pode manifestar-se com peculiaridade no processo infeccioso (TAYLOR et al., 2005a). Assim, em candídiases orais, SAP1 a SAP3 são importantes e SAP1,2,4 e 5 estão envolvidas com vaginites.Usando mutantes deficientes em genes de SAP foi possível evidenciar que a SAP6 está associada a infecção da córnea do olho durante a transformação de C. albicans leveduras para formas filamentosas (JACSON; WILBELMUS; HUBE, 2007)

C. albicans secreta também fosfolipases que são de extrema relevância no processo de invasão celular por lisarem a membrana fosfolipídica das células do hospedeiro. Dentre todas as fosfolipases, as mais estudadas são PLB1, PLB2, PLC1 e PLD1 (SAMARANAYAKE et al., 2006). Apesar de não ser bem elucidado o local de ação de todas as fosfolipases no processo de invasão ao hospedeiro, Calderone e Fonzi (2001) mostraram que a PBL1 é de fundamental importância na manifestação da candidíase sistêmica.

\section{Resposta imune à Candida albicans}

Os mecanismos imunes contra o fungo envolvem resposta imune inata (precoce) e imune adaptativa (tardia). As células do padrão $\mathrm{T}$ helper 1 (TH1), T helper 2 (TH2), T helper 17 (TH17) e $\mathrm{T}$ regulatórias (Tregs) com funções efetoras diferentes estão relacionadas com manifestações clínicas de diferentes graus de severidade ou superação da infecção ou ainda comensalismo (ROMANI; KAUFMANN, 1998; ROMANI, 2004; KOGUCHI; KAWAKAMI, 2002; HUFFNAGLE; DEEPE, 2003; CONCHON-COSTA et al., 2007; CONCHON-COSTA; FELIPE; GAZIRI，2008;
FELIPE et al., 2008).

\section{$O$ sistema imune inato}

Candida albicans é um fungo com capacidade patogênica, sendo o sistema imune um importante modulador desta resposta. A contenção da invasão do patógeno no hospedeiro exige uma resposta rápida, geralmente exercida pelo sistema imune inato, o qual desenvolve prontamente e precede a expansão clonal de linfócitos antígenosespecíficos. O sistema imune inato consiste de células Natural Killer, complemento, proteínas plasmáticas e células fagocíticas (ISMAIL et al., 2002). Ele tem efeito antifúngico direto pela destruição do patógeno e sinalização para as células do sistema imune adaptativo, por meio da produção de citocinas e de quimiocinas pró-inflamatórias, indução de atividades co-estimulatórias e apresentação de antígeno (ROMANI, 2004).

A resposta imune inata, também inclui as superfícies epiteliais, como a pele e os revestimentos dos tratos gastrintestinal, respiratório e genitourinário, que proporcionam uma barreira física contra esse microrganismo, pois interagem com o fungo e formam mecanismos imunes inatos nestes locais (ROMANI, 2002). As defensinas produzidas por células epiteliais do intestino participam no impedimento de translocação de C. albicans através do intestino (REHAUME; JOAULT; CHAMALLARD, 2010). O inflamasoma compreende uma plataforma molecular de componentes intracelulares oligomerizados, incluindo certos membros como: domínio oligomerização ligado a nucleotideo (NOD), domínio pirina contendo repetições ricas em leucina e proteína 3 (NLRP3). Mutação em NOD2 resulta em diminuição da produção de $\beta$ defensinas (REHAUME; JOAULT; CHAMALLARD, 2010). A Intreleucina-1 $\beta$ (IL-1 $\beta$ ) produzida pela célula mielóide modula a função de Th17 que participa da expressão de defensinas e outros fatores antifúngicos (CONTI et al., 2009). 


\section{O sistema de reconhecimento de padrões moleculares associados à patógenos}

O sistema imune distingue o próprio do não próprio do organismo através de receptores celulares encontrados nas células imunes chamadas de receptores de reconhecimento padrão (PRRs) que interagem com padrões moleculares presentes em microrganismos patogênicos (PAMPS). Esses receptores funcionam por quinases associadas a moléculas adaptadoras como o MyD88 para estimular a produção de substâncias microbicidas e citocinas nos fagócitos e incluem receptores tipo Toll e lectinas (AKIRA, 2003; MUKHOPADHYAY et al., 2004; TAYLOR et al., 2005 b). A expressão dos receptores e o reconhecimento pelo sistema imune geram respostas efetoras para a eliminação do patógeno e ativação da resposta imune adaptativa (CONCHON-COSTA; FELIPE; GAZIRI, 2008; LOYOLA et al., 2007; NETEA et al., 2008).

O Toll é originalmente definido como um gene da Drosophila, que está associado à resistência microbiana (HOFFMANN; REICHHART, 2002). O Toll tem sequência e domínios citoplasmáticos semelhantes aos dos receptores de IL-1, sendo observada a conservação evolutiva de ambos os sistemas sinalizadores celulares (O'NEILL; FITZGERALD; BOWIE, 2003).

As moléculas da superfície da Candida funcionam, desta maneira, como fatores de virulência que ativam o sistema imune, sendo estas, mananas, manoproteínas e glicolipídios (NETEA et al., 2004a; PIETRELLA et al., 2006; NETEA et al., 2008). Tais polissacarídeos e glicoconjugados são reconhecidos por várias lectinas que podem atuar independentemente ou em associação com receptores tipo Toll ou ainda com outros receptores de sinalização (CONCHON-COSTA et al., 2006; CONCHON-COSTA; FELIPE; GAZIRI, 2008). Os receptores dectina-1 podem reconhecer o ligante independente ou associado a receptores tipo Toll-2 para conferir responsividade a $\beta$-glucanas microbianas (BROWN et al., 2003; GANTNER;
SIMMONS; UNDERHILL, 2005; LOYOLA et al., 2007; ROSAS et al., 2008).

Outro tipo de lectina (CD-SIGN) é capaz de internalizar $C$. albicans por reconhecer estruturas complexas de manosídeos expostas nas células leveduriformes (CAMBI et al., 2003; TAYLOR et al., 2004; WELLS et al., 2008). Galectina-3, uma lectina originalmente descrita por sua ligação específica com a galactose, ligase a monosídeos $\beta-1,2$ específicos de Candida (FRADIN; POULAIN; JOUAULT, 2000) e também se associam a receptores tipo Toll-2 quando há interação de macrófagos com leveduras (JOUAULT et al., 2006).

A produção de citocinas pro-inflamatórias dependentes de receptores tipo Toll, como TNF- $\alpha$ e IL-1 $\beta$, e IL-10 ocasionalmente, pode ser ativada por $C$. albicans tanto no estado comensal quanto no patogênico (NETEA et al., 2004b; ROEDER et al., 2004). Os principais receptores tipo Toll para reconhecimento de $C$. albicans são do tipo 2 e 4 (GIL; GOZABLO, 2006a, 2006b). Estes dois tipos (Toll-2 e Toll-4) estão envolvidos na indução da produção de citocinas pro-inflamatórias e proteção do hospedeiro (NETEA et al., 2008).

O burst respiratório pode ser induzido pela sinalização dos PAMPs, e pode ser aumentado por citocinas inflamatórias como IFN- $\gamma$, IL-17, IL-6 e TNF- $\alpha$ (FARAH et al., 2009). O burst respiratório, compreende a produção das espécies reativas de oxigênio (EROs), ânion superóxido e peróxido de hidrogênio, e pela produção de peroxinitrito e seu intermediário óxido nitrico (NO) pelos macrófagos (GOUPIL et al., 2009). A produção desses compostos descritos acima é responsável tanto pela morte quanto pela inibição do crescimento de $C$. albicans por causarem quebra no DNA e produção de adultos de proteína e lipídios. Em humanos e camundongos, macrófagos e neutrófilos usam três sistemas oxidativos enzimáticos para eliminar $C$. albicans: fagócito oxidase (PHOX), que produz ânion superóxido; mieloperoxidase (MPO), 
produzindo radical hidroxil e ácido hipocloroso através de peróxido de hidrogênio; e a óxido nitrico sintase induzível (iNOS) que produz o radical óxido nítrico através da oxidação da L-arginina. O NO também é responsável por regular a expressão de mais de vinte citocinas, incluindo a IL-6, IL-12 e IFN- $\gamma$ e esta sinalização influencia tanto a ativação da resposta imune inata quanto à resposta imune adaptativa (FARAH et al., 2009).

Em resposta à infecção por $C$. albicans e através da sinalização pela enzima COX-2 temos a produção de prostaglandina E2 (PGE2) (LEVITIN; WHITEWAY, 2007; LEE et al., 2009), um potente regulador da resposta imune do hospedeiro. Dependendo da célula alvo, a PGE2 pode levar tanto a uma resposta pró quanto anti-inflamatória, isto é, PGE2 pode inibir uma resposta tipo Th1, fagocitose e proliferação de linfócitos assim como pode também promover uma resposta Th2 com produção de $\operatorname{IgE}$ e eosinofilia. A resposta Th1 na infecção por $C$. albicans é a responsável pela proteção e eliminação do patógeno, enquanto o desenvolvimento de resposta Th2 não é protetor, ao contrário, pode levá-la à cronicidade ou à sua disseminação (ERB-DOWNWARD; NOVERR, 2007).

Outra fonte potencial de síntese de prostaglandinas pode ser o próprio fungo patogênico. Erb-Downward e Noverr (2007) realizaram um trabalho para determinar a produção de PGE2 por Candida, e os resultados demonstraram que $C$. albicans pode produzir componentes de sinalização do sistema imune (PGE2) utilizando ácidos graxos disponíveis no hospedeiro, favorecendo sua persistência através da manutenção do padrão de resposta TH2. E uma vez que as condições favorecem o crescimento de C. albicans, a produção de PGE2 pode desempenhar um papel como um fator de virulência por "down" regular a fase efetora inata ou a resposta protetora TH1 à infecção. Esta produção de PGE2 por C. albicans ocorre via fosforilação de ERK $1 / 2$ e esta associado com ativação de NFkB (LEE et al., 2009).
Os neutrófilos têm um efeito importante no desenvolvimento de doenças fúngicas, visto que defeitos quantitativos e/ou qualitativos de neutrófilos levam à infecção fúngica disseminada, assim como ações imunoregulatórias (BODEY et al., 1966; WALSH; HIEMENZ; PIZZO, 1994; LOYOLA et al.,2002). Os macrófagos são células que residem em vários tecidos e possuem propriedade defensiva para o organismo por realizarem fagocitose e com isso eliminar os fungos. No entanto, os fungos possuem mecanismos de escape já mencionados anteriormente que proporcionam a sobrevida e disseminação fúngica (MANSOUR; LEVITZ, 2002; VAZQUEZ-TORRES; BALISH, 1997; GASPAROTO et al., 2004).

As células dendríticas são fagócitos que reconhecem o antígeno no tecido periférico, e migram para áreas de células $\mathrm{T}$ de órgãos linfóides fornecendo sinais necessários para ativação de células TH (ROMANI, 2004). As células dendríticas são capazes de fagocitar tanto leveduras quanto hifas de Candida, e podem fagocitar através de pseudópodes unilaterais, gerando um formato enrolado na superfície celular (por receptores de manose) quando interagem com leveduras ou podem fagocitar por pseudópodes bilaterais, formando uma estrutura de "zipper" (receptor Fc de anticorpos e receptor de complemento CR3), para hifas (ROMANI, 2004).

A ingestão de leveduras por receptores de manose resulta na produção de citocinas pro-inflamatórias, como IL-12 e TNF- $\alpha$, regulação positiva de moléculas co-estimulatórias e moléculas MHC-II, e ativação da resposta celular TH1 (SYME et al., 2002; MANSOUR; SCHLESINGER; LEVITZ, 2002). Essas respostas são suprimidas com a entrada do fungo via receptor de complemento 3 (CR3). A co-relação do CR3 e receptores da porção Fc de imunoglobulinas, na fagocitose de hifa ou na opsonização de levedura, resultam na produção de IL-4 e/ou IL-10, aumentando a regulação de moléculas co-estimulatórias e MHC-II, assim como a ativação de células TH2/Treg (ROMANI; 
BISTONI; PUCCETTI, 2002). Candida albicans que induzem apoptose quando opsonizadas com soro fresco de camundongo são ingeridas via CR3 aumentando a freqüência de macrófagos apoptóticos e diminuindo significativamente a produção de TNF- $\alpha$ comparado a ingestão via receptores de manose (GERALDINO et al., 2010).

A sinalização por via MyD88 é requerida para produção de IL-12 por células dendríticas desafiadas pela levedura com a implicação de distintos Tolls (IL-1R1 e TLR9) As células dendríticas das placas de Peyer do intestino possuem a propriedade de produzir IL-10 em resposta a Candida, sendo que esse evento ocorre mediado pela ativação via CR3 que requer opsonização por anticorpos (MONTAGNOLI et al., 2003), levando à ativação de células Treg CD4+CD25+. Tais células afetam negativamente a resposta das células $\mathrm{TH} 1$ antifúngicas (ROMANI; BISTONI; PUCCETTI, 2002), e podem servir como estratégia de adaptação do hospedeiro mamífero favorecendo-o futuramente.

Foi observado que o sistema imune possui papéis distintos frente à Candida dependendo do reconhecimento de morfotipos diferentes e da apresentação do antígeno o fungo terá um caráter comensal ou infeccioso. O uso de CR3, por exemplo, e consequente atenuação da produção de IL-12, favorece o comensalismo do fungo nas mucosas humanas, como intestino e vagina, onde a tolerância imune é desejável para o hospedeiro, sendo assim, a interação CR3 pode servir como uma importante estratégia evasiva do fungo (ROMANI, 2004)

\section{Imunidade adaptativa}

De acordo com Murphy (1989) os ensaios de reatividade sorológica e de pele indicavam que infecções fúngicas eram comuns porém, as doenças clínicas eram raras, consistente com o desenvolvimento de imunidade adaptativa. Em colonização fúngica sistêmica e de mucosas em camundongos, a resposta imune TH1 media proteção dependente de fagócitos e são os principais mediadores de imunidade protetora adquirida. Em contraste, produção de citocinas inibitórias por células TH2 tais como IL-4 e IL-10 estão associados com a progressão da doença (FÈ D’OSTIANI et al., 2000). Em indivíduos adultos imunocompetentes foi possível detectar uma resposta de hipersensibilidade do tipo tardia (HTT) e presume-se que esta resposta evite progressão de colonização de mucosas para infecção sintomática (ROMANI, 1999).

A infecção fúngica está associada a uma falha na imunidade mediada por células, (FLEMING, WALSH; ANAISSIE, 2002; HAGE; GOLDMAN; WHEAT, 2002). Estudos em micoses endêmicas evidenciam a doença severa correlacionada com o grau de falha da imunidade mediada por células, e com o aumento nos níveis de anticorpos (MAGEE; COX, 2002). Para que as células TH1 tenham uma ativação ótima, há a necessidade de sinalização pelos fagócitos e a produção de citocinas como IL-12, qual possui funções como diferenciação de células do padrão TH1 e produção de IFN- $\gamma$. Em adição, IFN- $\gamma$ ativa macrófagos, aumenta a expressão de MHC-I e II, e aumenta a apresentação de antígenos (ROMANI; PUCCETTI; BISTONI, 1997). Falha na sinalização de fagócitos efetores predispõe o paciente a infecções, limitam a eficácia terapêutica de antifúngicos e anticorpos e favorece a persistência e/ou comensalismo do fungo.

A IL-4 é uma citocina que pode determinar susceptibilidade a muitas infecções fúngicas por direcionar polarização TH2 e sua ausência favorece a imunidade TH1 frente ao fungo e diminui a diferenciação de células TH2 (ROMANI; KAUFMANN, 1998). Em candidíase mucocutânea crônica (CMC), a produção de citocinas TNF- $\alpha$, IL-4 e IL-5 foram em níveis normais, porém os pacientes produziram IL-12 e IFN- $\gamma$ em níveis inferiores que o normal, que poderia gerar uma incapacidade de montar uma resposta protetora mediada por células, 
provavelmente devida ao comprometimento de células fagocíticas para direcionar a polarização de células do tipo TH1 (CHOI et al., 2003; LILIC et al., 2003).

Células TH1 produzem IFN- $\gamma$ e estão envolvidas na imunidade mediada por células, células TH2 produzem IL-4 e contribuem para imunidade humoral, células TH17 produzem IL-21 e geram IL-17 (WEI et al., 2007), realizando assim, um importante papel na resposta imune para fungos e patógenos extracelulares. Células Treg. forkhead box proteína 3-positiva (FOXP3+) secretam TGF- $\beta$ e IL-10 e regulam negativamente células T efetoras, possibilitando assim o desenvolvimento da infecção (GAFFEN, 2008; ANDERSSON et al., 2008; OCHS; OUKKA; TORGERSON, 2009).

Células Treg CD4+CD25+ tem sido associadas a diversas patologias participando de um equilíbrio do sistema imune adquirido, servindo como controle da imunidade antifúngica (MURPHY, 1989). A administração de células Treg CD4+CD25+ evita a patologia inflamatória que está associada à eliminação dos patógenos. Em ratos com candidíase, células Treg CD4+CD25+, produzindo IL-10 e TGF- $\beta$ previnem eliminação completa do fungo no trato gastrointestinal, gera persistência ao fungo e permite o desenvolvimento de células de memória (ROMANI; BISTONI; PUCCETTI, 2002). A produção de IL-10 em altos níveis, afeta negativamente a produção de IFN- $\gamma$, que são identificados em candidíase crônica (ROILIDES et al., 1998; LILIC et al., 2003). A Candida albicans induz imunossupressão (como regulação) pela sinalização via receptor semelhante ao Toll-2 que aumenta a produção de IL-10 e a ativação de células Treg (NETEA et al., 2004c; SUTMULLER et al., 2006; DENNING et al., 2007).

Candidíase mucocutânea crônica está associada a outras doenças, e esta condição está relacionada à mutação de um gene que está envolvido na ontogênese de células Treg CD4+CD25+ (LISTON et al., 2003). Na candidíase mucocutânea crônica, o defeito na produção de citocinas do tipo TH1 não ocorre concomitantemente com o aumento da produção de citocinas do tipo $\mathrm{TH} 2$, mas, mais frequentemente, com aumento de IL-10, provavelmente por Treg (LILIC, 2002). Isso leva a especulação de que uma inerente alteração na sinalização mediada por receptor em resposta a polissacarídeos do fungo pode predispor pacientes com candidíase mucocutânea crônica a uma indução disfuncional de ativação de células Treg, afetando negativamente a eliminação fúngica dependente de células TH1, sem implicação na ativação de células TH2.

A ativação de distintos Toll de células dendríticas e a subsequente produção de IL-6 são eventos cruciais que medeiam a inibição da função de células Treg (AKIRA, 2003). Citocinas proinflamatórias, com exceção de IL-6, são produzidas por células epitelial orais e vaginal em resposta ao fungo, podendo assim regular negativamente a produção de IFN- $\gamma$ em alguns pacientes com recorrência de candidíase vaginal (FIDEL, 2002). A citocina sinalizadora das células Treg é TGF- $\beta$, e a linhagem específica do fator regulador e transcriptor (STAT) das células Treg são STAT-5 e FOXP3, respectivamente (YAO et al., 2007; ANDERSSON et al., 2008). Vários autores relataram que mutação no gene FOXP3 interfere com o desenvolvimento de células Treg e causa uma desregulação imune, assim como imunodeficiências, por exemplo, a síndrome da hiper-IgE autossômica dominante, que é causada por mutação do sinal transdutor e ativador da transcrição 3 (STAT3), prevenindo a diferenciação da linhagem TH17 e aumentando a susceptibilidade para infecções por espécies de Candida (CAUDY et al., 2007; BEAUCOUDREY et al., 2008; RENNER et al., 2008).

Houve falha no recrutamento de neutrófilos em camundongos "nockautes" em IL-23p19(-/-) e IL17RA(-/-), porém não em camundongos IL-12(-/-), e células TCR-alfa/beta foram mais importantes então que células TCR-gama/delta. Surpreendentemente, os camundongos deficientes em linhagem Th17 
produtora de citocina IL-22 foram moderadamente susceptíveis a candidíase orofaringeana, indicando que IL-17, melhor que IL-22 é vital em defesa contra candidiases orais. Assim, a linhagem Th17, agindo através de IL-17, confere dominante resposta à candidiase oral por meio de neutrófilos e fatores antimicrobianos (CONTI et al., 2009).

Manana de Candida, porém não zymosan, betaglucanas, agonistas de Toll-like receptor (TLR) ou NOD2 ligante MDP, induziram produção de IL-17 em ausência de anticorpos anti-CD3/ anti-CD28. A citocina IL-17 controla a resposta inflamatória mediada por neutrófilos. A produção de IL-17 induzida por Candida foi dependente de células apresentadoras de antígeno e receptores de manose em macrófagos demonstrando que manana de Candida não é simplesmente um estímulo mitogênico. A via TLR2/dectina-1, porém não TLR4 ou NOD2, amplificaram a produção de IL17 induzidas por receptores de manose (VAN DE VEERDONK et al., 2009).

\section{Considerações finais}

Muitas drogas antifúngicas podem causar citotoxicidade ao fígado e rins do hospedeiro quando usadas terapeuticamente, pelo fato dos fungos serem eucariontes e possuírem semelhança às células humanas. Não existem vacinas padronizadas para prevenir infecções fúngicas, uma situação atribuída à complexidade do patógeno e suas sofisticadas estratégias de sobrevivência no hospedeiro e evasão da resposta imune. Podemos considerar que a longevidade de Candida assim como sua transição de comensal para patogênica consiste na relação do fungo com o sistema imune. Sendo assim, é de grande relevância evidenciar os aspectos de sinalização dos receptores de fagócitos por serem moduladores da resposta imune frente à Candida assim como a importância de se conhecer o funcionamento do sistema imune na prevenção e superação de candidíases.

\section{Agradecimentos}

Programa de Pós-Graduação em Patologia Experimental, PROPPG-UEL, CAPES e Fundação Araucária.

\section{Referências}

AKIRA, S. Mammalian Toll-like receptors. Current Opinion in Immunology, London, v. 15, n. 1, p. 5-11, 2003.

ALMEIDA, R. S. C.; BRUNKE, S.; ALBRECHT, A.; THEWES, S.; LAUE, M.; EDWARDS, J. E.; FILLER, S. G.; HUBE, B. The hyphal-associated adhesin and invasin Als3 of Candida albicans mediates iron acquisition from host ferritin. PloS Pathogens, San Francisco, v. 4, n .11, p. 1-17, 2008.

ÁlVARES, C. A.; SVLDZLNSKI, T. I. E.; CONSOLARO, M.E. L. Candidíase vulvovaginal: fatores predisponentes do hospedeiro e virulência das leveduras. Jornal Brasileiro de Patologia Médica Laboratorial, Rio de Janeiro, v. 43, n. 5, p. 319-327, 2007.

ANDERSSON, J.; TRAN, D. Q.; PESU, M.; DAVIDSON, T. S.; RAMSEY, H.; O'SHEA, J. J. CD41FoxP31 regulatory $\mathrm{T}$ cells confer infectious tolerance in a TGFbeta-dependent manner. The Journal of Experimental Medicine, New York, v. 205, p. 1975-1981, 2008.

BASTOS, A. M. C.; BRAVO, R. S.; GOULART FILHO, R. A.; ISALAN, T. B.; BARRETO, N. A. Perfil das mulheres com processo inflamatório por Candida em resultados de colpocitologia oncológica numa clínica de DST. DST Jornal Brasileiro das Doenças Sexualmente Transmissiveis, Niterói, v. 15, n. 2, p. 26-38, 2003.

BEAUCOUDREY, L.; PUEL, A.; FILIPE-SANTOS, O.; COBAT, A.; GHANDIL, P.; CHRABIEH, M. Mutations in STAT3 and IL12RB1 impair the development of human IL-17-producing T cells. The Journal of Experimental Medicine, New York, v. 205, n. 7, p. 1543-1550, 2008.

BODEY, G. P.; BUCKLEY, M.; SATHE, Y. S.; FREIREICH, E. J. Quantitative relationships between circulating leukocytes and infection in patients with acute leukemia. Annals of Internal Medicine, Philadelphia, v. 64, n. 2, p. 328-340, 1966.

BRAZ, S. C. M.; MOTTA, C. M. S.; MASSA, D. M. L.; NEVES, R. P.; MAGALHÃES, O. M. C. Viabilidade, confirmação taxonômica e detecção enzimática de espécies de Acremonium preservadas sob óleo mineral na Coleção de Culturas University Recife Mycology. Revista da Sociedade Brasileira de Medicina Tropical, Rio de Janeiro, v. 42, n. 1, p. 63-66, 2009. 
BROWN, G. D.; HERRE, J.; WILLIANS, D. L.; WILLMENT, J. A.; MARSHALL, A. S.; GORDON, S. Dectin-1 mediates the biological effects of $\beta$-glucans. The Journal of Experimental Medicine, New York, v. 197, n. 9, p. 1119-1124, 2003.

CALDERONE, R. A.; FONZI, W. A. Virulence factors of Candida albicans. Trends in Microbiology, Camridge, v. 9, n. 7, p. 327-335, 2001.

CAMBI, A.; GIJZEN, K.; DE VRIES, J. M.; TORENSMA, R.; JOOSTEN, B.; ADEMA, G. J. The C-type lectin DC-SIGN (CD209) is an antigen-uptake receptor for Candida albicans on dendritic cells. European Journal of Immunology, Weinheim, v. 33, n. 3, p. 532-538, 2003.

CANNON, R. D.; HOLMES, A. R.; MASON, A. B.; MONK, B. C. Oral Candida: Clearance, Colonization, or Candidiasis?. Journal of Dental Research, Washington, v. 74, n. 5, p. 1152-1161, 1995.

CARDOSO, B. C. Efeito de antifúngicos em suspensões e biofilmes de Candida albicans e Candida dubliniensis. 2004. Dissertação (Mestrado em Engenharia de Bioprocessos) - Universidade do Minho, Braga.

CAUDY, A. A.; REDDY, S. T.; CHATILA, T.; ATKINSON, J. P.; VERBSKY, J. W. CD25 deficiency causes an immune dysregulation, polyendocrinopathy, enteropathy, X-linked-like syndrome, and defective IL10 expression from CD4 lymphocytes. Journal of Allergy and Clinical Immunology, Saint Louis, v. 119, n. 2, p. 482-487, 2007.

CHOI, E. H.; FOSTER, C. B.; TAYLOR, J. G.; ERICHSEN, H. C.; CHEN, R. A.; WALSH, T. J.; ANTTILA, V. J.; RUUTU, T.; PALOTIE, A.; CHANOCK, S. J. Association between chronic disseminated candidiasis in adult acute leukemia and common IL4 promoter haplotypes. The Journal of Infectious Diseases, Chicago, v. 187, n. 7, p. 1153-1156, 2003.

COLOMBO, A. L.; GUIMARÃES, T. Epidemiologia das infecções hematogênicas por Candida spp. Revista da Sociedade Brasileira de Medicina Tropical, Rio de Janeiro, v. 36, n. 5, p. 599-607, 2003.

CONCHON-COSTA, I.; FELIPE, I.; GAZIRI, L. C. J. Resposta imune a Candida albicans. Revista Semina: Ciências Biológicas e da Saúde, Londrina, v. 29, n. 1, p. 27-40, 2008.

CONCHON-COSTA, I.; LOYOLA, W.; GAZIRI, L. C. J.; CUSTODIO, L. A.; FELIPE, I. Low dose of concanavalin-A enhances innate immune response and prevents liver injury in mice infected with Candida albicans. FEMS Immunology and Medical Microbiology, Amsterdam, v. 49, n. 3, p. 330-336, 2007.
CONCHON-COSTA, I.; LOYOLA, W.; GAZIRI, L. C. J.; CUSTODIO, L. A.; FELIPE, I.. Low dose of concanavalin-A enhances innate immune response and prevents liver injury in mice infected with Candida albicans. RECENT ADVANCES IN PATTERN RECOGNITION. Toll 2006, Salvador. Poster 37... Massachusetts: University of Massachusetts, 2006.

CONTI, H. R.; SHEN, E.; NAYYAR, N.; STOCUM, E.; SUN, J. N.; LINDEMANN, M. J.; HO, A. W.; HAI, J. H.; YU, J. J.; JUNG, W. J.; FILLER, S. G.; MASSOWELCH, P.; EDGERTON, M.; GAFFEN, S. L. Th17 cells and IL-17 receptor signaling are essential for mucosal host defense against oral candidiasis. Journal of Experimental Medicine, New York, v. 206, n. 2, p. 299311, 2009.

CORDEIRO, S. N.; TURATO, E. R.; VICENTINI, R. M. R.; GONÇALVES, A. K. S.; GIRALDO, P. C. Hábitos de higiene e sexuais de mulheres com vulvovaginites recorrentes. DST Jornal Brasileiro das Doenças Sexualmente Transmissiveis, Niterói, v. 15, n. 2, p. 1519, 2003.

CULTLER, J. E. Putative virulence factors of Candida albicans. Annual Review of Microbiology, Palo Alto, v. 45, p. 187-218, 1991.

DENNING, T. L.; WANG, Y. C.; PATEL, S. R.; WILLIAMS, I. R.; PULENDRAN, B. Lamina propria macrophages and dendritic cells differentially induce regulatory and interleukin 17-producing $\mathrm{T}$ cell responses. Nature Immunology, New York, v. 8, n. 10, p. 1086-1094, 2007.

ERB-DOWNWARD, J. R.; NOVERR, M. C. Characterization of prostaglandin E2 production by Candida albicans. Infection and Immunity, Washington, v. 75, n. 7, p. 3498-3505, 2007.

FARAH, C. S.; SAUNUS, J. M.; HU, Y.; KAZOULLIS, A.; ASHMAN, R. B. Gene targeting demonstrates that inducible nitric oxide synthase is not essential for resistance to oral candidiasis in mice, or for killing of Candida albicans by macrophages in vitro. Oral microbiology and Immunology, Copenhagen, v. 24, n. 1, p. 83-88, 2009.

FÈ D’OSTIANI, B. C.; DEL SERO, G.; BACCI, A.; MONTAGNOLI, C.; SPRECA, A.; MENCACCI, A.; RICCIARDI-CASTAGNOLI, P.; ROMANI, L. Dendritic cells discriminate between yeast and hyphae of the fungus Candida albicans: implications for initiation of T helper cell immunity in vitro and in vivo. Journal of Experimental Medicine, New York, v. 191, n. 10, p 16611673, 2000.

FELIPE, I.; GAZIRI, L. C. J.; CONCHON-COSTA, I.; 
CUSTODIO, L. A. Candidíase: aspectos gerais e efeito de imunomoduladores. In: WATANABE, M. A. E.; ONO, M. A.; CECCHINI, R.; ITANO, E. N. (Org.). Tópicos em patologia experimental. Londrina: EDUEL, 2008. p. 5674.

FIDEL, P. L. Jr. The protective immune response against vaginal candidiasis: lessons learned from clinical studies and animal models. International Reviews of Immunology, Philadelphia, v. 21, n. 6, p. 515-548, 2002.

FLEMING, R. V.; WALSH, T. J.; ANAISSIE, E. J. Emerging and less common fungal pathogens. Infectious Disease Clinics of North America, Philadelphia, v. 16, n. 4, p. 915-933, 2002.

FRADIN, C.; POULAIN, D.; JOUAUlT, T. Beta1,2-linked oligomannosides from Candida albicans bind to a 32-kilodalton macrophage membrane protein homologous to the mammalian lectin galectin-3. Infection and Immunity, Washington, v. 68, n. 8, p. 43914398, 2000.

GAFFEN, S. L. An overview of IL-17 function and signaling. Cytokine, Philadelphia, v. 43, n. 3, p. 402-407, 2008 .

GANTNER, B. N.; SIMMONS, R. M.; UNDERHILL, D. M. Dectin-1 mediates macrophage recognition of Candida albicans yeast but not filaments. The EMBO Journal, Oxford, v. 24, n. 6, p. 1277-1286, 2005.

GASPAROTO, T. H.; GAZIRI, L. C. J.; BURGER, E.; ALMEIDA, R. S. C.; FELIPE, I. Apoptosis of phagocytic cells induced by Candida albicans and production of IL-10. FEMS Immunology and Medical Microbiology, Amsterdam, v. 142, n. 2, p. 219-224, 2004.

GERALDINO, T. H.; DE VITO, E.; CUSTÒDIO, L. A.; CONCHON-COSTA, I; GAZIRI, L. C. J.; FELIPE, I.; LOYOLA, W.; BONIFACIO, K. L. Increased tumour necrosis factor-alpha production, higher mannose receptor activity and ability to kill Candida by concanavalin-A activated macrophages. FEMS Immunology and Medical Microbiology, Amsterdam, v. 59, n. 1, p. 11-17, 2010.

GIL, M. L.; GOZALBO, D. About the role of TLR2 and TLR4 in cytokine secretion by murine macrophages in response to Candida albicans. FEMS Immunology and Medical Microbiology, Amsterdam, v. 46, n. 1, p. 1-2, 2006a.

GIL, M. L.; GOZALBO, D. TLR2, but not TLR4, triggers cytokine production by murine cells in response to Candida albicans yeasts and hyphae. Microbes and Infection, Paris, v. 8, n. 8, p. 2299-2304, 2006b.

GOUPIL, M.; TRUDELLE, E. B.; DUGAS, V.; RACICOT-BERGERON, C.; AUMONT, F.; SÉNÉCHAL, S.; HANNA, Z.; JOLICOEUR, P.;
REPENTIGNY, L. Macrophage-mediated responses to Candida albicans in mice expressing the human immunodeficiency virus type 1 transgene. Infection and Immunity, Washington, v. 77, n. 9, p. 4136-4149, 2009.

GUINDÓS, G.; SANCHES-VARGAS, L. O.; VILLAR-VIDAL, M.; ERASO, E.; ALKORTA, M.; HERNANDEZ-ALMARAZ, J. L. Activities of fluconazole and voriconazole against bloodstream isolates of Candida glabrata and Candida kruzei: a 14-year study in a Spanish tertiary medical centre. International Journal of antimicrobial agents, Amsterdam, v. 31, p 266-271, 2008.

HAGE, C. A.; GOLDMAN, M.; WHEAT, L. J. Mucosal and invasive fungal infections in HIV/AIDS. European Journal of Medical Research, Munich, v. 7, n. 5, p. 236241, 2002.

HOFFMANN, J. A.; REICHHART, J. M. Drosophila innate immunity: an evolutionary perspective. Nature Immunology, New York, v. 3, n. 2, p. 121-126, 2002.

HUBE, B.; NAGLIK, J. Candida albicans proteinases: resolving the mystery of a gene family. Microbiology, Washington, v. 147, p. 1997-2005, 2001.

HUFFNAGLE, G. B.; DEEPE, G. S. Innate and adaptive determinants of host susceptibility to medically important fungi. Current Opinion in Microbiology, Oxford, v. 6, n. 4, p. 344-350, 2003.

ISMAIL, N.; OLANO, J. P.; FENG, H.; WALKER, D. H. Current status of immune mechanisms of killing of intracellular microorganisms. FEMS Microbiology Letters, Amsterdam, v. 207, n. 2, p. 111-120, 2002.

JACSON, B. E.; WILBELMUS, K. R.; HUBE, B. The role of secreted aspartyl proteinases in Candida albicans keratitis. Investigative Ophthalmology \& Visual Science, Philadelphia, v. 48, n. 8, p. 3559-3565, 2007.

JOUAULT, T.; EL ABED-EL BEHI, M.; MARTINEZESPARZA, M.; BREUILH, L.; TRINEL, P. A.; CHAMAILLARD, M. Specific recognition of Candida albicans by macrophages requires galectin-3 to discriminate Saccharomyces cerevisiae and needs association with TLR2 for signaling. Journal of Immunology, Baltimore, v. 177, n. 7, p. 4679-4687, 2006.

JOUAULT, T.; SARAZIN, A.; MARTINEZ-ESPARZA, M.; FRADIN, C.; SENDID, B.; POULAIN, D. Host responses to a versatile commensal: PAMPs and PRRs interplay leading to tolerance or infection by Candida albicans. Cellular Microbiology, Oxford, v. 11, n. 7, p. 1007-1015, 2009.

KARKOWSKA-KULETA, J.; RAPALA-KOZIK, M.; KOZIK, A. Fungi pathogenic to humans: molecular bases of virulence of Candida albicans, Cryptococcus 
neoformans and Aspergillus fumigatus. Acta Biochimica Polonica, Warszawa, v. 56, n. 2, p. 211-224, 2009.

KIRKPATRICK, C. Host factors in defense against fungal infection. American Journal of Medicine, New York, v. 77, p. 1-12, 1984.

KOGUCHI, Y.; KAWAKAMI, K. Cryptococcal infection and TH1-TH2 cytokine balance. International Reviews of Immunology, Philadelphia, v. 21, n. 4/5, p. 423-438, 2002.

KULETA, J. K.; KOZIK, M. R.; KOZIK, A. Fungi pathogenic to humans: molecular bases of virulence of Candida albicans, Cryptococcus neoformans and Aspergillus fumigates. Acta Bichimica Polonica, Warszawa, v. 56, n. 2, p. 211-224, 2009.

LEE, H-S.; LEE, C. S.; YANG, C. J.; SU, S. L.; SALTER, D. M. Candida albicans induces cyclo-oxygenase 2 expression and prostaglandin E2 production in synovial fibroblasts through an extracellular-regulated kinase 1/2 dependent pathway. Arthritis Research \& Therapy, London, v. 11, n. 2, p. 1-9, 2009.

LEVITIN, A.; WHITEWAY, M. The effect of prostaglandin E2 on transcriptional responses of Candida albicans. Microbiological research, Jena, v. 162, n. 3, p. 201-210, 2007.

LILIC, D. New perspectives on the immunology of chronic mucocutaneous candidiasis. Current Opinion in Infectious Diseases, Philadelphia, v. 15, n. 2, p. 143-147, 2002.

LILIC, D.; GRAVENOR, I.; ROBSON, N.; LAMMAS, D.A.; DRYSDALE, P.; CALVERT, J. E.; CANT, A. J.; ABINUN, M. Deregulated production of protective cytokines in response to Candida albicans infection in patients with chronic mucocutaneous candidiasis. Infection and Immunity, Washington, v.71, n.10, p. 56905699, 2003.

LIMA, T. D.; FERNANDES, O. F. L.; SOUZA, H. L. K.; PASSOS, S. X.; SILVA, M. R. R. Candida albicans de mucosa vaginal: morfotipagem e produção de proteinase. Revista de Patologia Tropical, Goiania, v. 33, n. 1, p. 6570, 2004.

LISTON, A.; LESAGE, S.; WILSON, J.; PELTONEN, L.; GOODNOW, C. C. Aire regulates negative selection of organ-specific T cells. Nature Immunology, New York, v. 4, n. 4, p. 350-435, 2003.

LOYOLA, W.; CONCHON-COSTA, I.; GAZIRI, L. C. J.; FELIPE, I. Phagocytosis of Candida albicans by macrophages from mice pretreated with extract of Artocarpus integrifolia is mediatedby dectin-1 receptors. In: INTERNATIONAL CONGRESS OF IMMUNOLOGY. 13 ${ }^{\text {th }}$, 2007, Rio de Janeiro. Session poster... Rio de Janeiro: Arthritis Research \& Therapy, 2007.

LOYOLA, W.; GAZIRI, D.A.; GAZIRI, L. C. J.; FELIPE, I. Concanavalin-A ehances phagocytosis and killing of Candida albicans by mice peritoneal neutrophils and macrophages. FEMS Immunology and Medical Microbiology, Amsterdam, v. 33, n. 3, p. 201208, 2002.

MAGEE, D. M.; COX, R. A. In Fungal pathogenesis. In: CALDERONE, R. A.; CIHLAR, L. R. (Ed.). Principles and clinical applications. New York: Dekker, Inc., 2002. p. 279-292.

MANSOUR, M. K.; LEVITZ, S. M. Interactions of fungi with phagocytes. Current Opinion in Microbiology, Oxford, v. 5, n. 4, p. 359-365, 2002.

MANSOUR, M. K.; SCHLESINGER, L. S.; LEVITZ, S. M. Optimal $\mathrm{T}$ cell responses to Cryptococcus neoformans mannoprotein are dependent on recognition of conjugated carbohydrates by mannose receptors. Journal of Immunology, Baltimore, v. 168, n. 6, p. 28722879, 2002.

MONTAGNOLI, C.; BOZZA, S.; BACCI, A.; GAZIANO, R.; MOSCI, P.; MORSCHHÄUSER, J.; PITZURRA, L.; KOPF, M.; CUTLER, J.; ROMANI, L. A role for antibodies in the generation of memory antifungal immunity. European Journal of Immunology, Weinheim, v. 33, n. 5, p. 1193-1204, 2003.

MUKHOPADHYAY, S.; HERRE, J.; BROWN, G. D.; GORDON, S. Linking yeast PAMPs to direction of immune response. Cellular Microbiology, Oxford, v. 11, p. 1007-1015, 2004.

MURPHY, J. W. Immunity to fungi. Current Opinion in Microbiology, Oxford, v. 2, p. 360-367, 1989.

NETEA, M. G.; BROWN, G. D.; KULLBERG, B. J.; GOW, N. A. An integrated model of the recognition of Candida albicans by the innate immune system. Nature Reviews Microbiology, London, v. 6, n. 1, p. 67-78, 2008.

NETEA, M. G.; VAN DER GRAAF, C.; VAN DER MEER, J. W.; KULLBERG, B. J. Recognition of fungal pathogens by Toll-like receptors. European Journal of Clinical Microbiology \& Infectious Diseases, Wiesbaden, v. 23 , n. 9 , p. $672-76,2004 a$.

NETEA, M. G.; VAN DER GRAAF, C.; VAN DER MEER, J. W.; KULLBERG, B. J. Toll-like receptors and the host defense against microbial pathogens: bringing specificity to the innate-immune system. Journal of Leukocyte Biology, New York, v. 75, n. 5, p. 749-755, 2004b.

NETEA, M.G.; SUTMULLER, R.; HERMANN, C.; 
VAN DER GRAAF, C. A.; VAN DER MEER, J. W.; VAN KRIEKEN, J. H. Toll-like receptor 2 suppresses immunity against Candida albicans through induction of IL-10 and regulatory T cells. Journal of Immunology, Baltimore, v. 172, n. 6, p. 3712-3718, 2004c.

O'NEILL, L. A.; FITZGERALD, K. A.; BOWIE, A. G. The Toll-IL-1 receptor adaptor family grows to five members. Trends in Immunology, London, v. 24, n. 6, p. 286-290, 2003.

OCHS, H. D.; OUKKA, M.; TORGERSON, T. R. TH 17 cells and regulatory $\mathrm{T}$ cells in primary immunodeficiency disease. Journal of Allergy and Clinical Immunology, Saint Louis, v. 123, n. 5, p. 977-983, 2009.

OLIVEIRA, J. M.; CRUZ, A. S.; FONSECA, A. F.; VAZ, C. P.; RODRIGUES, A.; AUREA, F. Prevalence of Candida albicans in vaginal fluid of asymptomatic Portuguese women. The Journal of Reproductive Medicine, Chicago, v. 38, n. 1, p. 41-42, 1993.

PFALLER, M. A.; DIEKEMA, D. J. Epidemiology of invasive candidiasis: a persistent public health problem. Clinical Microbiology Review; Iowa, v. 20 p. 133-163, 2007.

PHAN, Q. T.; MYERS, C. L.; FU, Y.; SHEPPARD, D. C. YEAMAN, M. R.; WELCH, W. H.; IBRAHIM, A. S.; EDWARDS JR, J. E.; FILLER, S. G. Als3 is a Candida albicans invasin that binds to cadherins and induces endocytosis by host cells. PloS Biology, San Francisco, v. 5, n. 3, p. 543-557, 2007.

PIETRELlA, D.; BISTONI, G.; CORBUCCI, C.; PERITO, S.; VECCHIARELLI, A. Candida albicans mannoprotein influences the biological function of dendritic cells. Cellular Microbiology, Oxford, v. 8, n. 4, p. 602-612, 2006.

REHAUME, L. M.; JOAULT, T; CHAMALLARD, M. Lessons from the inflammasome: a molecular sentry linking Candida and Crohn's disease. Trends in Immunology, London, v. 31, n. 5, p. 171-175, 2010.

RENNER, E. D.; RYLAARSDAM, S.; ANOVERSOMBKE, S.; RACK, A. L.; REICHENBACH, J.; CAREY, J. C. Novel signal transducer and activator of transcription 3 (STAT3) mutations, reduced $\mathrm{T}(\mathrm{H}) 17$ cell numbers, and variably defective STAT3 phosphorylation in hyper-IgE syndrome. Journal of Allergy and Clinical Immunology, Saint Louis, v. 122, n. 1, p. 181-187, 2008.

ROEDER, A.; KIRSCHNING, C. J.; RUPEC, R. A.; SCHALLER, M.; WEINDL, G.; KORTING, H. C. Toll-like receptors as key mediators in innate antifungal immunity. Medical Mycology, Oxford, v. 42, n. 6, p. 485498, 2004.

ROILIDES, E.; SEIN, T.; SCHAUFELE, R.; CHANOCK,
S. J.; WALSH, T. J. Increased serum concentrations of interleukin-10 in patients with hepatosplenic candidiasis. The Journal of Infectious Diseases, Chicago, v. 178, n. 2, p. 589-592, 1998.

ROMANI, L. Immunity to Candida albicans: TH1, TH2 cells and beyond. Current Opinion Infectious Diseases, London, v. 2, n. 4, p. 363-367, 1999.

ROMANI, L. Immunity to fungal infections. Nature Reviews Microbiology, London, v. 4, p. 1-13, 2004.

ROMANI, L. In fungal pathogenesis. In: CALDERONE, R. A.; CIHLAR, L. R. (Ed.). Principles and clinical applications. New York: Dekker, Inc., 2002. p. 401-432.

ROMANI, L.; BISTONI, F.; PUCCETTI, P. Fungi, dendritic cells and receptors: a host perspective of fungal virulence. Trends in Microbiology, Cambridge, v. 10, n. 11, p. 508-514, 2002.

ROMANI, L.; KAUFMANN, S. H. Immunity to fungi. Research in Immunology, Paris, v. 149, p. 281-493, 1998.

ROMANI, L.; PUCCETTI, P.; BISTONI, F. Interleukin-12 in infectious diseases. Clinical Microbiology Reviews, Washington, v. 10, n. 4, p. 611-636, 1997.

RÖRIG, K. C. O.; COLACITE, J.; ABEGG, M. A. Produção de fatores de virulência in vitro por espécies patogênicas do gênero Candida. Revista da Sociedade Brasileira de Medicina Tropical, Rio de Janeiro, v. 42, n. 2, p. 225-227, 2009.

ROSAS, M.; LIDDIARD, K.; KIMBERG, M.; FAROTRINDADE, I.; MCDONALD, J. U.; WILLIAMS, D. L. The induction of inflammation by dectin-1 in vivo is dependent on myeloid cell programming and the progression of phagocytosis. Journal of Immunology, Baltimore, v. 181, p. 3549-3557, 2008.

SAMARANAYAKE, Y. H.; DASSANAYAKE, R. S.; JAYATILAKE, J. A.; CHEUNG, B. P.; YAU, J. Y.; YEUNG, K. W.; SAMARANAYAKE, L. P. Differential phospholipase gene expression by Candida albicans in artificial media and cultured human oral epithelium. Acta Pathologica, Microbiologica et Immunologica, Copenhagen, v. 114, n. 12, p. 857-866, 2006.

SOLL, D. R.; LOCKHART, S. R.; ZHAO, R. Relationship between Switching and Mating in Candida albicans. Eukaryotic Cell, Washington, v. 2, n. 3, p. 390-397, 2003.

SUTMULLER, R. P.; DEN BROK, M. H.; KRAMER, M.; BENNINK, E. J.; TOONEN, L. W.; KULLBERG, B. J. Toll-like receptor 2 controls expansion and function of regulatory T cells. Journal of Clinical Investigation, New York, v. 116, n. 2, p. 485-494, 2006.

SYME, R. M.; SPURRELL, J. C.; AMANKWAH, E. K.; GREEN, F. H.; MODY, C. H. Primary dendritic cells 
phagocytose Cryptococcus neoformans via mannose receptors and $\mathrm{Fc} \gamma$ receptor II for presentation to $\mathrm{T}$ lymphocytes. Infection and Immunity, Washington, v. 70, n. 11, p. 5972-5981, 2002.

TAYLOR, B. N.; STAIB, P.; BINDER, A.; BIESEMEIER, A.; SEHNAL, M.; RÖLLINGHOFF, M.; MORSCHHÄUSER, J.; SCHRÖPPEL, K. Profile of Candida albicans-Secreted Aspartic Proteinase Elicited during Vaginal Infection. Infection and Immunity, Washington, v. 73, n. 3, p. 1828-1835, 2005a.

TAYLOR, P. R.; BROWN, G. D.; HERRE, J.; WILLIAMS, D. L.; WILLMENT, J. A.; GORDON, S. The role of SIGNR1 and the beta-glucan receptor (Dectin-1) in the nonopsonic recognition of yeast by specific macrophages. Journal of Immunology, Baltimore, v. 172, p. 1157-1162, 2004.

TAYLOR, P. R.; MARTINEZ-POMARES, L.; STACEY, M.; LIN, H. H.; BROWN, G. D.; GORDON, S. Macrophage receptors and immune recognition. Annual Review of Immunology, Palo Alto, v. 23, p. 901-944, 2005b.

VAL, I. C. C.; ALMEIDA FILHO, G. L. Abordagem atual da candidíase vulvovaginal. DST Jornal Brasileiro das Doenças Sexualmente Transmissíveis, Niteói, v. 13, n. 4 , p. 3-5, 2001.

VAN DE VEERDONK, F. L.; MARIJNISSEN, R. J.; KULLBERG, B. J.; KOENEN, H. J.; CHENG, S. C.; JOOESTEN, I.; VAN DEN BERG, W. B.; WILLIANS, D. L.; VAN DER MEER, J. W.; JOOSTEN, L. A.; NETEA, M. G. The macrophage mannose receptor induces IL17 in response to Candida albicans. Cell Host Microbe, Cabridge, v. 23, n. 4, p. 311-313, 2009.

VAZQUEZ-TORRES, A.; BALISH, E. Macrophages in resistance to candidiasis. Microbiology and Molecular Biology Reviews, New York, v. 61, n. 2, p. 170-192, 1997.

WALSH, T. J.; HIEMENZ, J.; PIZZO, P. A. Evolving risk factors for invasive fungal infections-all neutropenic patients are not the same. Clinical Infectious Diseases, Chicago, v. 18, n. 4, p. 793-798, 1994.

WEI, L.; LAURENCE, A.; ELIAS, K. M.; O'SHEA, J. J. IL-21 is produced by Th17 cells and drives IL-17 production in a STAT3-dependent manner. Journal of Biological Chemistry, Bethesda, v. 282, p. 34605-34610, 2007.

WELLS, C. A.; SALVAGE-JONES, J. A.; LI, X.; HITCHENS, K.; BUTCHER, S.; MURRAY, R. Z. The macrophage inducible C-type lectin, mincle, is an essential component of the innate immune response to Candida albicans. Journal of Immunology, Baltimore, v.
180, n.11, p. 7404-7413, 2008.

WILLIAMS, D. W.; POTTS, A. J.; WILSON, M. J.; MATTHEWS, J. B.; LEWIS, M. A. Characterisation of the inflammatory cell infiltrate in chronic hyperplastic candidosis of the oral mucosa. Journal of Oral Pathology \& Medical, Singapore, v. 26, n. 2, p. 83-89, 1997.

YAO, Z.; KANNO, Y.; KERENYI, M.; STEPHENS, G.; DURANT, L.; WATFORD, W. T. Nonredundant roles for Stat5a/b in directly regulating Foxp3. Blood, New York, v. 109, n. 10, p. 4368-4375, 2007.

ZHAO, X.; OH, S. H.; CHENG, G.; GREEN, C. B.; NUESSEN, J. A.; YATER, K.; LENG, R. P.; BROWN, A. J. P.; HOYER, L. L. Als3 and Als8 represent a single locus that encodes a Candida albicans adhesion; functional comparisons between Als3 and Als1. Microbiology, Washington, v. 150, p 2415-2428, 2004.

Recebido em 30 de setembro de 2009 - Received on September 30, 2009

Aceito em 28 de junho de 2010 - Accepted on June 28, 2010 